\title{
Development of Absorbed Blasting Vibration Energy Index for the Evaluation of Human Comfort in Multistorey Buildings
}

\author{
Qiang Yao, ${ }^{1,2}$ Xingguo Yang, ${ }^{1,2}$ and Hongtao $\mathrm{Li}^{1,2}$ \\ ${ }^{1}$ State Key Laboratory of Hydraulics and Mountain River Engineering, Sichuan University, Chengdu, Sichuan 610065, China \\ ${ }^{2}$ College of Water Resource and Hydropower, Sichuan University, Chengdu, Sichuan 610065, China \\ Correspondence should be addressed to Hongtao Li; htl@scu.edu.cn
}

Received 9 February 2017; Accepted 3 May 2017; Published 31 May 2017

Academic Editor: Isabelle Sochet

Copyright ( 2017 Qiang Yao et al. This is an open access article distributed under the Creative Commons Attribution License, which permits unrestricted use, distribution, and reproduction in any medium, provided the original work is properly cited.

\begin{abstract}
There have been civil disputes and complaints regarding the negative effects of blasting vibration on buildings around the blasting site. By considering the effect of blasting vibration on a human body as a process of energy transfer and conversion, the human body absorbed blasting vibration energy (ABVE) index has been developed for comfort evaluation. Using dynamic monitoring and theoretical analysis, the elevation amplification effect and selective amplification effect on different frequency components of the ABVE have been investigated. The elevation amplification factor and selective amplification coefficients on different frequency components of the ABVE index for a typical 4-storey brick and concrete building have been determined. Based on the results, the magnitude and frequency components of the ABVE index in different parts especially in different storeys for the typical building have been determined. According to the characteristics of human body's response to vibrations of different frequencies, the frequency-based weighting method of ABVE index has been simplified. By calculating the combined effect of vibrations from all directions, the total human body ABVE and its frequency components at different floors of the building can be determined accurately. This can be used to evaluate the human body comfort against blasting vibration at different floors.
\end{abstract}

\section{Introduction}

In recent years, with more projects in hydropower, railway, highway, and urban construction, there is more blasting near residences and businesses. As such, the number of civil disputes, complaints and lawsuits induced by the blasting has been increasing $[1,2]$. Many studies have shown that human body is sensitive to the blasting vibrations. The sensitivity of human body is more than 10 times greater than that of buildings $[3,4]$. At present, when blasting operations are conducted near residential areas, attention tends to be paid only to the impact of blasting vibrations on the safety of buildings $[5,6]$. The vibration strength which meets the vibration comfort requirement is less than the safety limit for cosmetic cradling. Hence, the complaints and disputes cannot be solved from the perspective of structural safety [7]. Rather than safety, the problem is a typical issue of comfort that needs to resolve the annoyance, anxiety, and even complaints of residents, which are mainly caused by annoyance effects of blasting activities, fear of building damage, and disturbance effects $[7,8]$. In recent years, blasting vibration comfort has become a research topic in United States, Canada, United Kingdom, Australia, and India [9-13]. The problem, as many researchers put it, has transferred from limiting structural damage to reducing lawsuits. The sensitivity of people to vibration is an important area and a new research topic in studying blasting vibration $[14,15]$.

There are many factors that affect the reaction of people to blasting vibration. The main factors are the amplitude, frequency, and duration of blasting vibration [16-18]. Currently, the widely used indices for the evaluation of the blasting vibration comfort are the blasting vibration peak intensity in United States, Canada, United Kingdom, and Australia, maximum weighted vibration intensity $\left(\mathrm{KB}_{F \max }\right)$ in Germany, quadric vibration dose value (VDV) internationally, and annoyance rate index in China [18]. While the blasting vibration peak intensity is easy to understand and to determine, it neglects the effects of frequency and duration 
of the blasting vibration. The maximum weighted vibration intensity, $\mathrm{KB}_{F \max }$, is the weighted peak vibration velocity by frequency [19]. In order to calculate the VDV index, the monitored blasting vibration velocity data needs to be converted into acceleration through mathematic approach, which likely imports some calculating errors [20-22]. The comfort evaluation index of annoyance rate proposed by Song [23] is more complicated and is still in doubt with respect to its applicability to the transient vibration.

For different comfort evaluation methods, the comfort evaluation criteria are also different. Reference [24] suggests that the peak particle velocity (PPV) should not be greater than $10 \mathrm{~mm} / \mathrm{s}$, and, for PPV $>5 \mathrm{~mm} / \mathrm{s}$, it should be limited to $5 \%$ probability. For long-term blasting vibration, PPV should be lower than $2 \mathrm{~mm} / \mathrm{s}$. Zhang et al. [25] developed the humanization control indexes for blasting vibration. The thresholds for the ground sensible vibration and the psychologically acceptable vibration are $0.7 \mathrm{~mm} / \mathrm{s}$ and $5 \mathrm{~mm} / \mathrm{s}$, respectively. Yu [26] studied the reaction of a multistorey building and the people inside the building to the blasting vibration. He developed the vibration control indexes for day time, which are $3 \mathrm{~mm} / \mathrm{s}(<10 \mathrm{~Hz}), 3-5 \mathrm{~mm} / \mathrm{s}(10-50 \mathrm{~Hz})$, and $5-7 \mathrm{~mm} / \mathrm{s}(>50 \mathrm{~Hz})$. Li and Deng [27] evaluated the effects of blasting vibration on human comfort. They found that, for $\mathrm{KB}_{F \max }<3.0$, the peak vibration velocity is $<5 \mathrm{~mm} / \mathrm{s}$. At this level, the blasting vibration does not annoy humans. Wu et al. [28] used the blasting monitoring data and found that the negative impact of blasting vibration is lowest and the harmonic production can be achieved when the acceleration is less than $110 \mathrm{~dB}$. By analyzing the wavelet analysis energy evaluation index $\mathrm{E}_{k}$ and combining it with engineering practice, Chen et al. [29] developed the comfort evaluation method. Currently, there are various blasting vibration comfort indexes and standards and the difference between them is large. Hence, it can be concluded that different blasting vibration comfort evaluation methods and standards are different and, sometimes, the evaluation results are even the opposite [18].

As high-rise buildings exhibit dynamic responses to blasting vibration, people inside buildings, especially highrise buildings, are affected by the energy and frequency of the blasting vibration. Yu [26] monitored the vibration response at different buildings and at different heights. He found that with low frequencies of blasting vibration, high-rise buildings can produce large vibration amplification effect. On the other hand, with frequencies much higher than the natural frequency of the building, the vibration amplification with the floor is not increased easily. Y. Zhang and Y. Zhang [30] monitored and numerically simulated the vibration velocity of buildings located above tunnels. They found that the peak vibration velocity showed significant amplification effect which increases with building height. Wang et al. [31] carried out field tests and numerical simulation studies on the dynamic response of framed buildings under blasting vibration. They found that the vibration velocity was amplified significantly when the natural frequency of the building was close to that of the blasting vibration. Wierschem et al. [32] validated the efficacy of a proposed passive nonlinear mitigation system to rapidly and efficiently attenuate the global structural response. Currently, research on the amplification effect has been used to evaluate the safety of buildings. However, there is little research on the effect of blasting vibration energy on human comfort in multistorey buildings. The mentioned comfort evaluation methods, such as the blasting vibration peak intensity, maximum weighted vibration intensity $\mathrm{KB}_{F \max }$, and quadratic VDV, are those on the ground. Hence, sometimes when an evaluation gives a comfort conclusion, it does not fully reflect human comfort in the actual situation.

In this study, first, the human absorbed blasting vibration energy (ABVE) index on the comfort evaluation has been developed. Through analysis of a typical 4 -storey brick and concrete building and human vibration characteristics, the elevation amplification effects on ABVE and frequency-based quantitative influence coefficients have been determined. By correcting the ABVE evaluation index quantitatively, the total blasting vibration energy and frequency components received by people at different floors have been accurately determined. As compared to the traditional evaluation methods, the method developed in this study is more accurate and more objective in the evaluation of the blasting vibration comfort.

\section{Absorbed Blasting Vibration Energy (ABVE)}

The human body is not only affected by the blasting vibration intensity but also by the vibration frequency, duration, and other dynamic factors. In this study, the effect of blasting vibration on people is considered as an energy transfer and conversion. Blasting is an energy source, blasting seismic waves can be considered as energy carriers, and a human body inside a building can be treated as an energy acceptor. The final reaction of a human body can be seen as the reaction results of the receptor. Under certain input and deformation conditions, the body can be regarded as a linear system. A linear parameter centralized system can be used to approximate a vibration system consisting of lifeless mass, flexible and damping elements. Different body parts have their natural vibration frequency. When the blasting seismic waves are transmitted to the floor or seats that are in contact with the body, the vibration energy is transferred into the body, and the energy is transmitted along the body. Energy transfer and conversion concepts can be used to evaluate the vibration response of the human body, which is referred to as the "absorbed blasting vibration energy (ABVE)" [33]. The ABVE can be used as a parameter to characterize the interaction between humans and the vibration environment. Based on the assumptions of human energy transmission and absorption, the absorbed blasting vibration energy per unit time can be described as power, and the mechanical simulation of power can be described as work. As absorbed energy is a measure of the dissipated energy input by the vibration, the absorbed energy by the body during time $T$ can be expressed as follows:

$$
E=\int_{0}^{T} F(t) \cdot V(t) d t
$$

where $E$ is the absorbed energy by the body; $F(t)$ is a function of the input force; and $V(t)$ is a function of the input speed. 


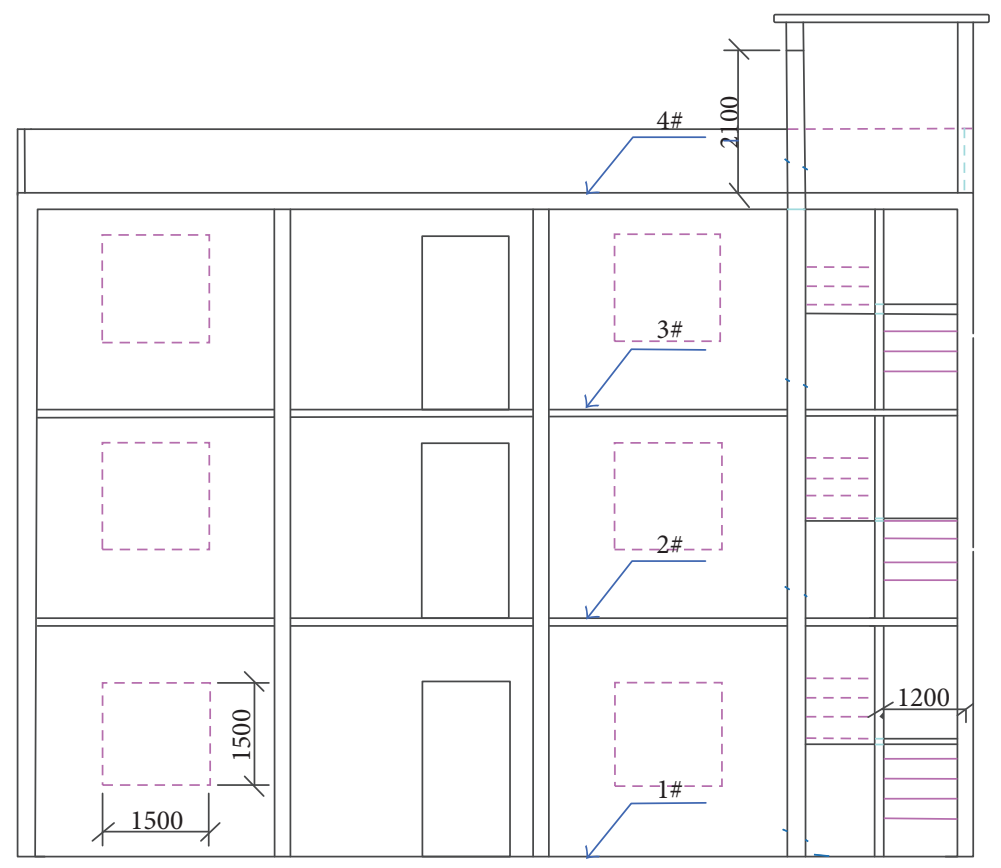

FIgURE 1: The vibration monitoring points.

ABVE index is a scalar that has a definite physical meaning and is suitable for periodic and random vibration inputs. The vibrating kinetic energy is considered for evaluating BV comfort [34]. Assuming that the mass is denoted by $\Delta m$, the absorbed energy at time $t$ is determined by

$$
E=\frac{1}{2} \Delta m v^{2}(t)
$$

where $E$ represents the BV energy and $v(t)$ is the BV velocity. Equation (2) can be rewritten as

$$
E=v^{2}(t) .
$$

Therefore, ABVE at time $t$ can be expressed by the square of the corresponding velocity. With integration, the absorbed energy during a certain period can be determined by

$$
E_{T}=\int_{t_{1}}^{t_{2}} v^{2}(t) d t
$$

where $E_{T}$ represents the absorbed energy during a certain period and $t_{1}$ and $t_{2}$ are the starting time and ending time, respectively.

Since the monitored BV velocities are discrete digital signals, (4) can be rewritten as

$$
E=\left(\sum_{i=1}^{i=n} v^{2}\left(t_{i}\right)\right) * \Delta t
$$

where $v\left(t_{i}\right)$ is the discrete digital signal of BV velocity, $n$ is the total number of samples, and $\Delta t$ is the sampling interval.

The total blasting vibration energy $E$ accounts for the change in energy over time without including the effect of frequency. The power spectral density $\operatorname{PSD}(f)$ can describe the relative magnitude of the harmonic component energy within a certain frequency range. Based on the spectral analysis on the blasting vibration velocity, different frequency bands $f_{i}$ and the corresponding power spectral density $\mathrm{PSD}_{i}$ can be determined. Then, the ratio of the energy in any one of the frequency bands $\left(f_{m} \leq f<f_{n}\right)$ to the total energy is

$$
P_{E_{f}}=\frac{\sum_{i=m}^{n-1} \mathrm{PSD}_{i}}{\sum \mathrm{PSD}_{i}}
$$

where $P_{E_{f}}$ is the proportion of the energy within the frequency range $f_{m} \leq f<f_{n}$ in the total energy.

After determining the blasting vibration energy and the spectral analysis of the blasting vibration signal, the entire frequency domain has been segmented. Combining (5), (6), and (7), the energy ratio and magnitude in each frequency band and the total absorbed blasting vibration energy can be determined.

$$
E_{f}=P_{E_{f}} \cdot E
$$

\section{Dynamic Response Characteristics of Multistorey Buildings to Blasting Vibration Load}

Buildings respond to blasting vibration dynamically. To accurately determine the blasting vibration energy received by a human body in different parts of a building, it is necessary to ascertain the dynamic response of the building. To gain further quantitative understanding of the amplification effect of the building floor elevation on the blasting vibration energy, response of a four-storey brick and concrete building has been monitored. Figure 1 shows that the vibration monitoring 
TABLE 1: The amplification factor of the absorbed blasting vibration energy at each floor.

\begin{tabular}{lccc}
\hline Floor & & Amplification factor $\gamma_{E}$ & Horizontal tangential \\
Foundation & Horizontal radial & 1 & Vertical direction \\
Second floor & 1 & 1.3 & 1 \\
Third floor & 1.9 & 1.7 & 1.23 \\
Fourth floor & 2.2 & 2.3 & 2.61 \\
\hline
\end{tabular}

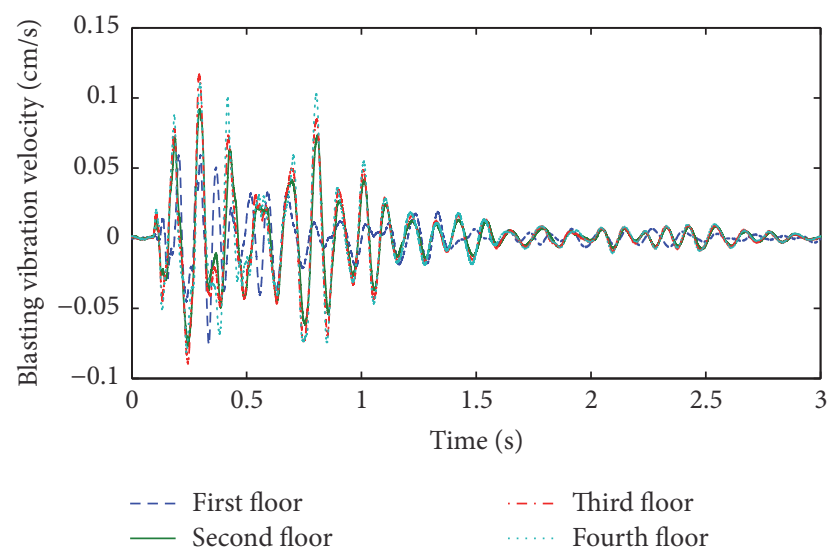

FIGURE 2: The typical blasting vibration waveforms at each floor.

points of \#1 \#4 are at the building foundation (first floor), second floor, third floor, and fourth floor, respectively. There are 20 groups of blasting vibration velocity monitoring data. Figure 2 shows typical blasting vibration waveforms at each floor. This is an indication that the building has responded to the blasting vibration. There is also more blasting vibration energy at the higher floor. According to a statistical analysis of the 20 groups of data, Figure 3 shows the amplification of the peak particle velocity. It can be seen that the peak velocity fluctuates in each direction. Using the calculation method for the ABVE index in Section 2, the total blasting vibration energy at all the floors in all the directions has been determined. Figure 4 and Table 1 show the amplification factor of the ABVE at each floor, which means the ratio of ABVE of each layer to the ABVE of the foundation layer. It can be seen that the amplification is greater at the higher floor. This suggests that the people at the higher floor will absorb more blasting vibration energy than those at the lower floor. Based on the monitoring data, the quantitative energy amplification factors of each floor in the 4-storey brickconcrete building have been determined, as shown in Table 1 .

\section{Building Response to Different Frequency Components of Blasting Vibration Energy}

4.1. Selected Amplification Effect of Buildings on Different Frequency Components of Blasting Vibration Energy. Due to the complexity of the blasting vibration frequency components and the vibration characteristics of buildings, there is

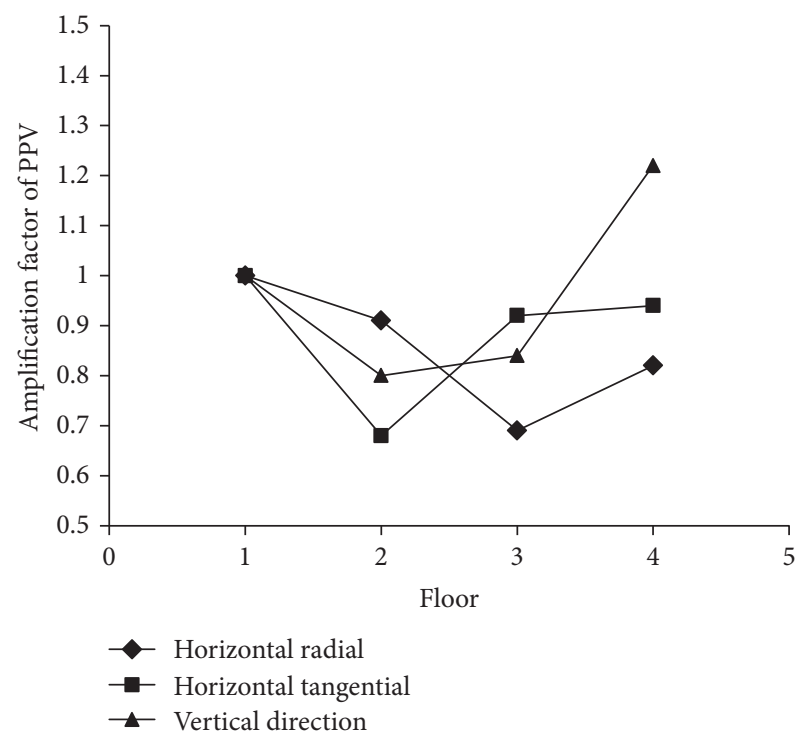

FIGURE 3: The amplification of the peak particle velocity.

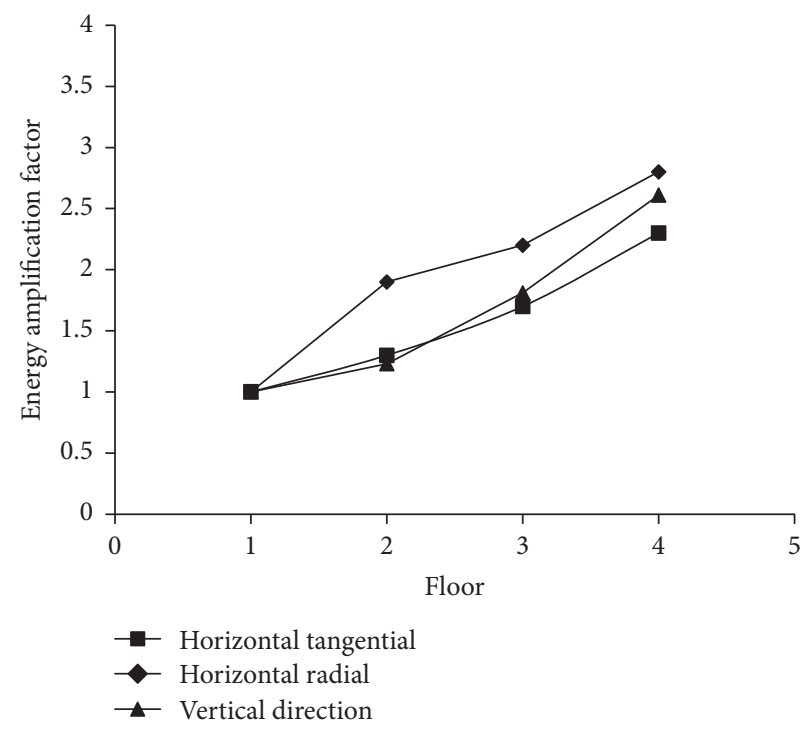

FIgURE 4: The amplification factor of the blasting vibration energy at each floor.

a selective amplification of the blasting vibration wave by the buildings. Blasting earthquakes contain many frequency 


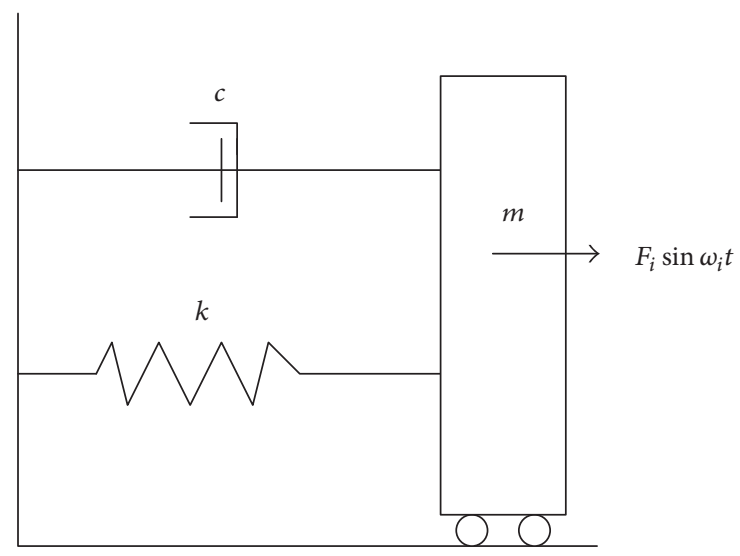

FIGURE 5: The forced vibration model of a single degree of freedom system with damping.

components, which can be considered as superpositions of sine or cosine functions of different frequencies. Further, the building response to seismic blasting can be considered as a superposition of vibration excitation responses of different frequency components. When blasting vibration wave enters the structure, the structure amplifies certain frequency components, which are close to or the same as the natural frequency of the structure and component of the structure, and allows them to pass through. For the other frequency components which are not close to the natural frequency of the structure, they are filtered out or suppressed $[35,36]$.

The building response to different frequency components of blasting vibration can be studied by forced vibration of a single degree of freedom system with linear damping. Blasting seismic wave may be considered as the superposition of a series of sine waves.

$$
A(t)=\sum_{i=1}^{n} A_{i} \sin \left(\omega_{i} t+\varphi_{i}\right),
$$

where $A_{i}$ is the amplitude of $i$ th sine wave component, $\omega_{i}$ is the circular frequency of $i$ th sine wave component, and $\varphi_{i}$ is the first phase of $i$ th sine wave component.

Assume that there is a component in the blasting seismic wave with its acceleration being

$$
a_{i}=a \sin \omega_{i} t,
$$

where $a$ is the amplitude of the acceleration and $\omega_{i}$ is the angular velocity of the sine wave component.

To simplify the calculations, the structural system has been assumed to have only a single degree of freedom. The forced vibration model of a single degree of freedom system with damping is shown in Figure 5.

In a single degree of freedom system, the equivalent compulsion force on the system is

$$
F=F_{i} \sin \omega_{i}(t),
$$

where $F_{i}=-m a$. The dynamic equation is

$$
m \ddot{x}+c \dot{x}+k x=F_{i} \sin \omega_{i}(t)
$$

where $m, c$, and $k$ are mass, viscous damping coefficient, and stiffness of the system, respectively; $x$ is the structural displacement; $\dot{x}$ is the structural vibration velocity; and $\ddot{x}$ is the acceleration of the structural vibration.

Then,

$$
\ddot{x}+2 \zeta_{0} \omega_{0} \dot{x}+\omega_{0}^{2} x=\frac{F_{i}}{m} \sin \omega_{i}(t),
$$

where $\omega_{0}=\sqrt{k / m}$ is the natural frequency of the system and $\zeta_{0}=c / 2 m \omega_{0}$ is the damping ratio of the system.

Since the external load $\left(F_{i} / m\right) \sin \omega_{i} t$ changes harmonically, a particular solution of the equation can be assumed as

$$
x=N_{1} \sin \omega_{i} t+N_{2} \cos \omega_{i} t,
$$

where $N_{1}$ and $N_{2}$ are the undetermined coefficients.

Selecting appropriate $N_{1}$ and $N_{2}$, we have

$$
\begin{aligned}
& {\left[\left(\omega_{0}^{2}-\omega_{i}^{2}\right) N_{1}-2 \zeta_{0} \omega_{i} \omega_{0} N_{2}-\frac{F_{i}}{m}\right] \sin \omega_{i} t} \\
& \quad+\left[\left(\omega_{0}^{2}-\omega_{i}^{2}\right) N_{2}-2 \zeta_{0} \omega_{i} \omega_{0} N_{1}\right] \cos \omega_{i} t=0 .
\end{aligned}
$$

Since $\sin \omega_{i} t$ and $\cos \omega_{i} t$ alternate between -1 and 1 , there are

$$
\begin{aligned}
\left(\omega_{0}^{2}-\omega_{i}^{2}\right) N_{1}-2 \zeta_{0} \omega_{i} \omega_{0} N_{2}-\frac{F_{i}}{m} & =0, \\
\left(\omega_{0}^{2}-\omega_{i}^{2}\right) N_{2}+2 \zeta_{0} \omega_{i} \omega_{0} N_{1} & =0 .
\end{aligned}
$$

Then,

$$
\begin{aligned}
& N_{1}=\frac{F_{i}}{m} g \frac{\omega_{0}^{2}-\omega_{i}^{2}}{\left(\omega_{0}^{2} \omega_{i}^{2}\right)^{2}+4 \zeta_{0} \omega_{i}^{2} \omega_{0}^{2}}, \\
& N_{2}=\frac{F_{i}}{m} g \frac{-2 \zeta_{0} \omega_{i} \omega_{0}}{\left(\omega_{0}^{2} \omega_{i}^{2}\right)^{2}+4 \zeta_{0} \omega_{i}^{2} \omega_{0}^{2}} .
\end{aligned}
$$

Assume

$$
\begin{aligned}
& N_{1}=A \cos \varphi, \\
& N_{2}=-A \sin \varphi .
\end{aligned}
$$

Use constants $A$ and $\varphi$ to substitute $N_{1}$ and $N_{2}$; then

$$
\begin{aligned}
A & =\sqrt{N_{1}^{2}+N_{2}^{2}} \\
& =x g \frac{1}{\sqrt{\left(1-\omega_{i}^{2} / \omega_{0}^{2}\right)^{2}+4 \zeta_{0}^{2}\left(\omega_{i}^{2} / \omega_{0}^{2}\right)}}, \\
\tan \varphi & =-\frac{N_{2}}{N_{1}}=\frac{2 \zeta_{0}\left(\omega_{i} / \omega_{0}\right)}{1-\left(\omega_{i} / \omega_{0}\right)^{2}},
\end{aligned}
$$

where $x$ is the static displacement under the effect of dynamic load amplitude $F$.

By defining that $f_{0}$ is the natural frequency of the structure, $f_{i}$ is the excitation frequency of the blasting vibration component, and $\lambda=f_{i} / f_{0}$ under the effect of blasting 


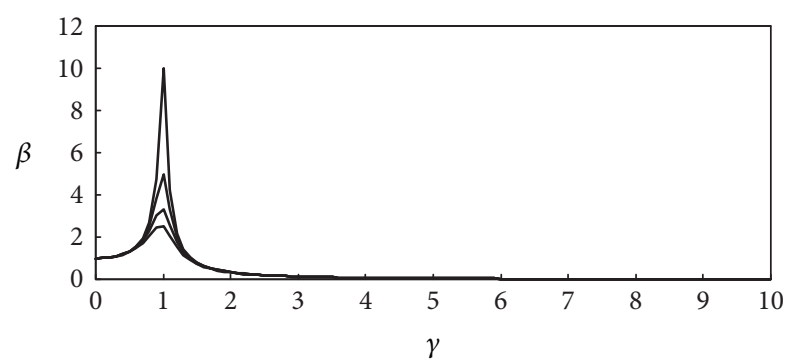

FIgURE 6: Amplitude frequency characteristic curve of a single free system (the damping is $0.05,0.1,0.15$, and 0.2 from top to bottom according to the peak value).

vibration load component $F_{i} \sin \omega_{i} t$, the displacement amplification factor of the structure is [37]

$$
\begin{aligned}
\beta & =\frac{A}{x}=\frac{1}{\sqrt{\left(1-f_{i}^{2} / f_{0}^{2}\right)^{2}+4 \zeta_{0}^{2}\left(f_{i}^{2} / f_{0}^{2}\right)}} \\
& =\frac{1}{\sqrt{\left(1-\lambda^{2}\right)^{2}+4 \zeta_{0}^{2} \lambda^{2}}} .
\end{aligned}
$$

From (19), the dynamic amplification factor $\beta$ is relevant not only to the frequency ratio $\lambda$ but also to the structural damping ratio $\zeta_{0}$. For different values of $\zeta_{0}$, the relationship between the dynamic amplification factor and the frequency ratio can be determined, as shown in Figure 6. The damping ratio, $\zeta_{0}$, of real-life engineering structures is typically small, from 0.02 to 0.1 [37].

As can be seen in Figure 6, under harmonic excitation, the displacement amplification factor of the building is entirely determined by the frequency of the harmonic force, natural frequency of the building (structure), and the damping ratio. When the excitation frequency is close to the natural frequency of the structure, if the damping ratio of the structure is small, the vibration response amplification factor is large. Otherwise, the amplification factor is small. For different damping ratios, when $\gamma=1$, the system displacement amplification factor is largest. Under this condition, the amplification factor reaches its maximum, which is affected by the damping ratio. When the frequency ratio is not equal to 1 , that is, the excitation frequency is not close to the natural frequency, the displacement amplification factor is small. When the excitation frequency shifts to lower frequency, the amplification factor approaches to 1; while the excitation frequency shifts to higher frequency, amplification factor drops rapidly and approaches 0 . When the excitation frequency is twice the natural frequency, the displacement amplification factor is about 0.3 . For systems with high frequencies, the damping ratio has little effect on the amplification factor.

The blasting vibration can be considered as the superposition of harmonic waves of different frequencies. If these harmonic components are considered separately, based on the discussion on the single degree of freedom system, when they are acting on the same building but with different frequencies, the corresponding displacement amplification factors are also different. Only the harmonic components

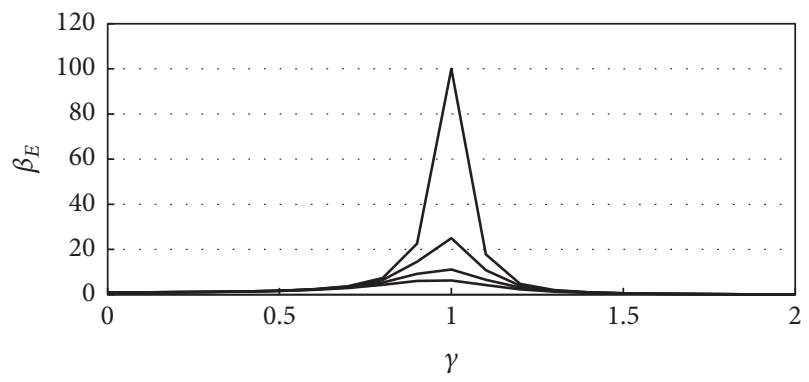

FIGURE 7: The energy frequency characteristic curve of a single degree freedom system (the damping is $0.05,0.1,0.15$, and 0.2 from top to bottom according to the peak value).

close to the natural frequency of building have the maximum amplification. The harmonic components with relatively low frequencies can substantially maintain their amplitudes. On the other hand, the harmonic components with frequencies higher than the natural frequency of the building may be weakened. The response characteristics of buildings to different harmonic components can therefore be understood by selecting an amplification effect on the energy components with different frequencies in the blasting seismic waves.

Express the blasting vibration harmonic component as

$$
u=A \sin \omega t,
$$

where $u$ is the displacement; $A$ is the displacement amplitude; and $\omega$ is the circular frequency. The speed history can be expressed as

$$
v=A \omega \cos \omega t .
$$

According to the definition of (4), the blasting vibration energy is

$$
E=(A \omega)^{2} \cos ^{2} \omega t
$$

The relationship between the energy amplitude and the displacement amplitude is

$$
E_{A}=(A \omega)^{2} .
$$

Combining (23) with (19), the energy amplification factor becomes

$$
\beta_{E}=\frac{1}{\left(1-\gamma^{2}\right)^{2}+(2 h \gamma)^{2}}
$$

Similar to the displacement amplification factor, using (24), the energy frequency characteristic curve of a single degree freedom system has been determined, as shown in Figure 7.

As shown in Figure 7, for $\gamma=1$, the extreme values of the energy amplification factor are 100, 25, 11.1, and 6.25. The effects of the damping ratios on the amplification factors are significant. For a blasting vibration process with many frequency components, when the structural damping ratio, $h=0.1$, is applied to the structure, the energy component 
TABLE 2: The natural frequency of common buildings.

\begin{tabular}{|c|c|c|c|c|c|}
\hline $\begin{array}{l}\text { Building } \\
\text { categories }\end{array}$ & $\begin{array}{l}\text { Structure } \\
\text { type }\end{array}$ & Building type & $\begin{array}{l}\text { Building } \\
\text { storey } \\
\text { number }\end{array}$ & $\begin{array}{c}\text { Natural } \\
\text { vibration } \\
\text { period (s) }\end{array}$ & $\begin{array}{c}\text { Natural } \\
\text { vibration } \\
\text { frequency } \\
(\mathrm{Hz})\end{array}$ \\
\hline \multirow{7}{*}{ Civil } & \multirow{4}{*}{$\begin{array}{c}\text { Brick } \\
\text { concrete } \\
\text { structure }\end{array}$} & Civil house & $1 \sim 2$ & $0.1 \sim 0.2$ & $5.0 \sim 10.0$ \\
\hline & & Office & 3 & 0.34 & 2.9 \\
\hline & & Dormitory & 3 & 0.25 & 4.0 \\
\hline & & Dormitory & $4 \sim 7$ & $0.36 \sim 0.60$ & $1.7 \sim 2.8$ \\
\hline & \multirow{3}{*}{$\begin{array}{c}\text { Frame shear } \\
\text { structure }\end{array}$} & Cast-in situ concrete structure & 11 & 0.51 & 2.0 \\
\hline & & Precast fabricated concrete & 13 & 0.53 & 1.9 \\
\hline & & Residential building & $12 \sim 13$ & $0.65 \sim 0.75$ & $1.3 \sim 1.5$ \\
\hline
\end{tabular}

with frequencies that are close to the natural frequency of the structure are amplified 25 times. On the other hand, those with lower frequencies remain essentially unchanged and those with higher frequencies are suppressed. Therefore, due to the structural response, the relative proportions of vibration energy have been changed significantly. The energy component with frequencies that are close to the natural frequency of the structure becomes very prominent.

For harmonic components in the blasting vibration, when the amplitude is the same, only the harmonic energy with frequency close to the natural frequency of the building can be amplified to the maximum extent. Due to the selected amplification effect of the building to different energy components, the blasting vibration becomes very sensitive when its frequencies are close to the natural frequency. Based on the blasting comfort analysis of the blasting vibration characteristics and the dynamic properties of buildings, the sensitive frequency band has been determined, which is $5-80 \mathrm{~Hz}$.

\subsection{Frequency-Weighted Absorbed Blasting Vibration Energy} in Buildings. Define the weight of the blasting vibration energy of each frequency as $p_{E_{i}}$, which can be determined using (6). Further, the weight of the blasting vibration energy components of each frequency affected by the building is defined as $\beta_{E_{i}}$, which can be determined using the energy amplification factors in (24). Then, the participating weight $\alpha_{E_{i}}$ accounts for the effects of energy in various frequencies on the building, which can be determined as follows:

$$
\begin{aligned}
& \beta_{E_{i}}=\frac{1}{\left(1-\gamma_{i}^{2}\right)^{2}+\left(2 h \gamma_{i}\right)^{2}}, \\
& \alpha_{E_{i}}=\frac{\beta_{E_{i}}}{\sum \beta_{E_{i}}},
\end{aligned}
$$

where $\beta_{E_{i}}$ is the energy amplification factor of each frequency band; $\gamma_{i}=f_{i} / f_{n}$ is frequency ratio; $f_{n}$ is the natural frequency of the building; and $h$ is the damping ratio of the building.

From (25), the amplification factor $\beta$ is the structural energy response factor under the effect of blasting vibration. From (25), the structural vibration energy response factor is closely related to the natural frequency and damping ratio of the building. When the excitation frequency of the blasting vibration is close to the natural frequency of the building, the damping ratio of the building is small, and the corresponding vibration energy response factor is large; that is, the vibration response is large. Otherwise, the vibration response is small. Thus, according to the structural vibration energy response factor, the energy response factor of each frequency band under the effect of blasting vibration can be determined.

According to composition of blasting vibration energy and the effects of energy with different frequency bands on the building, the frequency of vibration energy is weighted. This energy-weighted value is known as the frequencyweighted absorbed blasting vibration energy of the building.

$$
E_{f_{i}}=E_{i} \cdot \gamma_{E_{i}} \cdot p_{E_{i}} \cdot \alpha_{E_{i}},
$$

where $E_{f_{i}}$ is the $i$ th frequency band-weighted response energy, $E_{i}$ is the blasting vibration energy of each band on the foundation, $\gamma_{E_{i}}$ is the elevation amplification factor of the building, $p_{E_{i}}$ is the proportion of the energy of $i$ th frequency band $f_{i}$, and $\alpha_{E_{i}}$ is the weight of the $i$ th frequency band that has been affected by the building.

By summing up the frequency-weighted response energy of each band, the frequency-weighted blasting vibration energy of the building under the effect of blasting vibration can be determined. With the frequency-weighted blasting vibration energy, it does reflect not only the effects of the three elements of the blasting vibration but also the response of inherent characteristics of the building to blasting vibration energy. In this study, the structural damping ratio is $h=$ 0.05 . The natural frequency of buildings is generally less than $10 \mathrm{~Hz}$, and the building only has amplification effect for certain frequency components. Hence, the entire frequency range has been divided into several frequency bands, and the weight corresponding to each band has been determined based on the natural frequency of the building.

This study focuses on the open-air blasting at groundlevel structures by an explosive source. As shown in Table 2, the natural frequency of common buildings is mainly within $1 \sim 10 \mathrm{~Hz}$. For a given building, in addition to the natural frequency listed in Table 2, there are higher order natural frequencies. Thus, $10 \mathrm{~Hz}$ has been taken as the reference natural frequency of the building. 


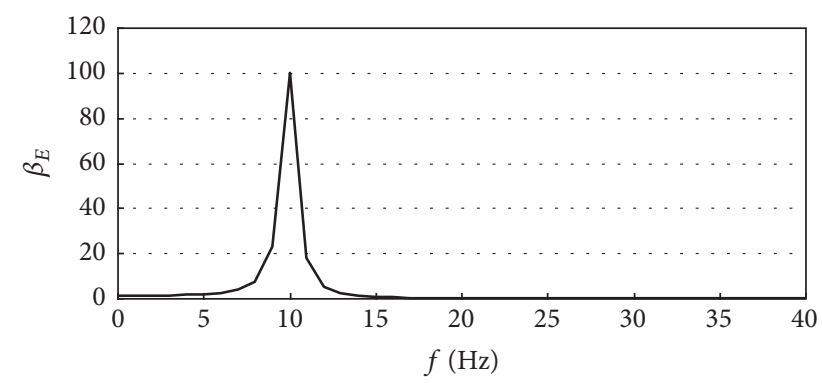

FIgURE 8: The calculated frequency characteristics curve of the energy.

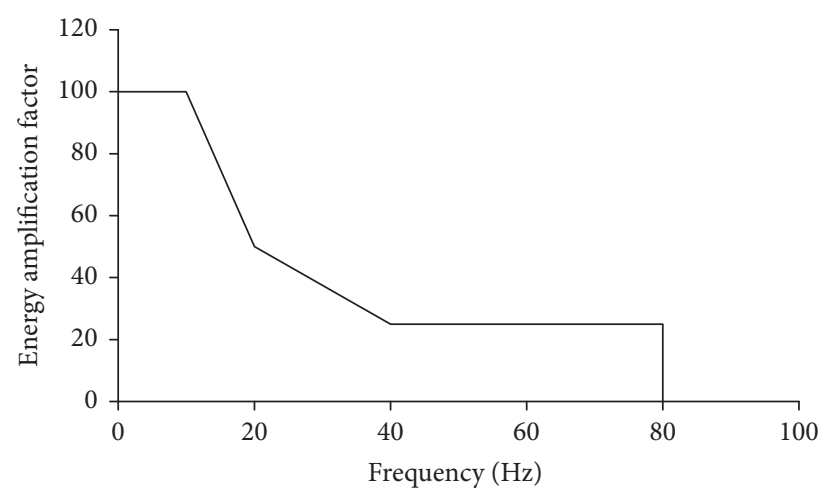

FIGURE 9: The corrected energy amplification factors.

TABLE 3: The energy weighting factor for each frequency band.

\begin{tabular}{lccccc}
\hline Sequence number & 1 & 2 & 3 & 4 & 5 \\
\hline Frequency band $(\mathrm{Hz})$ & $0 \sim 10$ & $10 \sim 20$ & $20 \sim 40$ & $40 \sim 80$ & $>80$ \\
Energy amplification factor & 100 & 75 & 37.5 & 25 & 0 \\
Weighting factor $\alpha_{E_{i}}$ & 0.4211 & 0.3158 & 0.1579 & 0.1053 & 0 \\
\hline
\end{tabular}

For a building with the natural frequency of $10 \mathrm{~Hz}$ and the structural damping ratio of 0.05 , Figure 8 shows the calculated frequency characteristics curve of the energy for this building.

As for the existence of high modes for buildings, according to the security control standard by the United States, Office of Surface Mine Reclamation Authority (OSMRE), the frequency range has been divided into five segments: $0 \sim 10 \mathrm{~Hz}, 10 \sim 20 \mathrm{~Hz}, 20 \sim 40 \mathrm{~Hz}, 40 \sim 80 \mathrm{~Hz}$, and $>80 \mathrm{~Hz}$. The calculated and the corrected energy amplification factors are shown in Figure 9 [38, 39].

Based on the results in Figure 9, the average frequency band has been determined. Further, using (25), the energy weighting factor for each frequency band has been determined, as shown in Table 3.

\section{Human Body Frequency-Weighted Response Energy}

Human body is very sensitive to vibrations and blasting, and its feeling towards them is complex and affected by a number of factors. Even for blasting vibrations of the same amplitude, the human feelings are different for different vibration directions and frequencies. Studies have shown that, for the same vibration, the responses of a human body and a building structure are very different. Building structure is more sensitive to low frequency vibrations, while the body is more sensitive to high frequency vibrations $[20,21]$. The reaction and endurance of a human body to vibration are totally different to those of buildings.

The sensitivity of human body is different for different vibration frequency. Thus, to evaluate the human comfort to vibration, the vibration frequency is a basic parameter. The human body is particularly sensitive to the vibrations within $1 \sim 80 \mathrm{~Hz}$, since the main natural vibration frequencies of several organs in the body are within $1 \sim 80 \mathrm{~Hz}$. When exposed to an environment whose frequency is close to the natural vibration frequency of human organs, those organs resonant. As such, the amplitude increases rapidly and produces relative displacement, thereby causing people to feel uncomfortable. Thus, even though the building elevation amplification and the frequency weighting of the absorbed blasting vibration energy have been evaluated, the body frequency weighting response still needs to be determined in order to achieve a more accurate evaluation of the impact of blasting vibration on the human body.

Blast vibration is transitory phenomenon lasting for a second or so. There is only limited literature on the response of the human body and communities to blasts. Several researchers recognized that the duration of vibration was critical to its undesirability [40-42]. Wiss and Parmelee [40] conducted a shaking table test to provide acceleration thresholds for different perception levels of vertical transient vibrations, which are the most objectionable type of vibrations in the floors of residential buildings. Forty subjects were subjected to various series of vibration input signals having frequencies ranging from 2.5 to $25 \mathrm{~Hz}$, amplitudes ranging from 0.00254 to $2.51 \mathrm{~mm}$, and damping ratios ranging from 1 to $10 \%$. The signals were generated for simulating a vibration induced by one-foot fall impact having a duration ranging between 0.33 and 5 seconds. Wiss and Paramelee [40] demonstrated that the human response to transitory vibrations is related to damping of the motion rather than frequency.

Siskind et al. [43] attempted to correlate the response with human annoyance. Siskind et al. [43] reported that particle velocities of $0.5 \mathrm{in} / \mathrm{s}$ from typical blasting (1 s vibration) had to be tolerable to about $95 \%$ of the people perceiving it as "distinctly perceptible." They pointed out also to the importance of the blast duration in forming of human response. Generally, as blast duration increases, the potential for adverse human response increases.

The vibration limits required for reasonable comfort from a long-term vibration source are certainly more restrictive than for sources of short duration and infrequent occurrence. Transient vibrations characterized by larger amplitudes and 


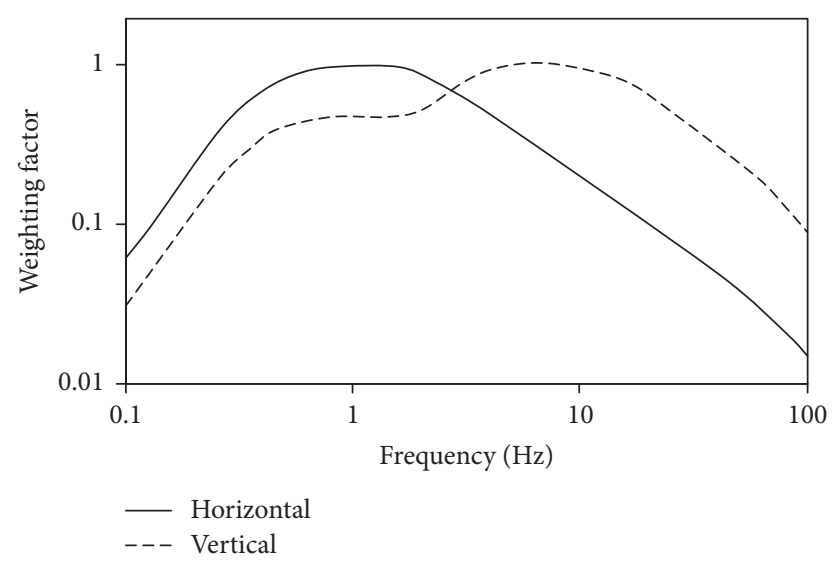

FIGURE 10: The 1/3 times bandwidth frequency weighting methods in ISO 2631.

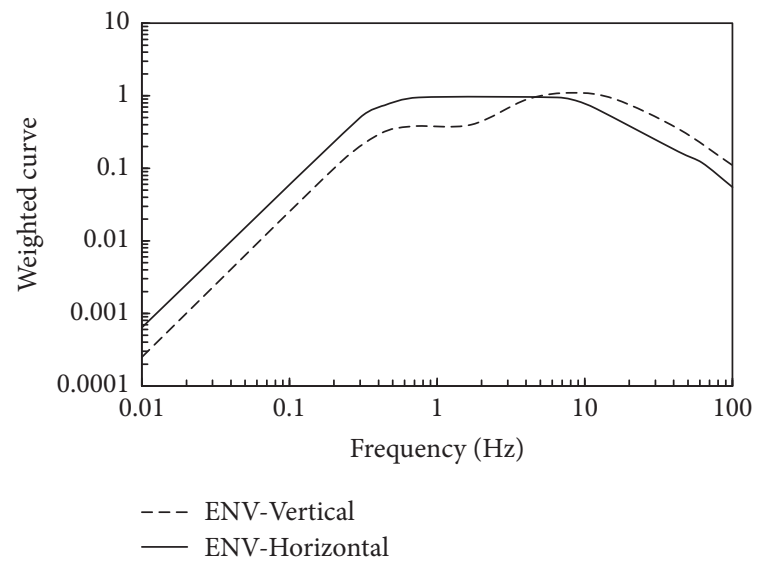

FIGURE 11: The frequency-weighted curve within $0.01 \sim 100 \mathrm{~Hz}$ in ENV 12299.

quick dissipation are more easily tolerated by humans than a continuous steady-state vibration [44]. Therefore, at a given amplitude, human perception is much greater under steady state than under transient vibrations, and steady-state vibrations are more likely to be viewed as annoying. This difference becomes important when vibrations are applied and evaluated for design purposes. Therefore, a good planned shot duration (generally less than $2 \mathrm{~s}$ ) has a high priority in blasting practice to provide human comfort [17].

ISO 2631 does not contain vibration exposure limits. People expose to periodic, random, and transient mechanical vibration which can interfere with comfort, activities, and health. For vibration signal frequency-weighted methods, there are frequency-domain filtering weighting methods of international standards such as the entire frequency weighting and 1/3 times bandwidth frequency weighting methods, as shown in Figure 10. In 2009, the EU issued a business comfort evaluation criteria ENV 12299, which specifies the frequencyweighted curve within $0.01 \sim 100 \mathrm{~Hz}$, as shown in Figure 11 [45].

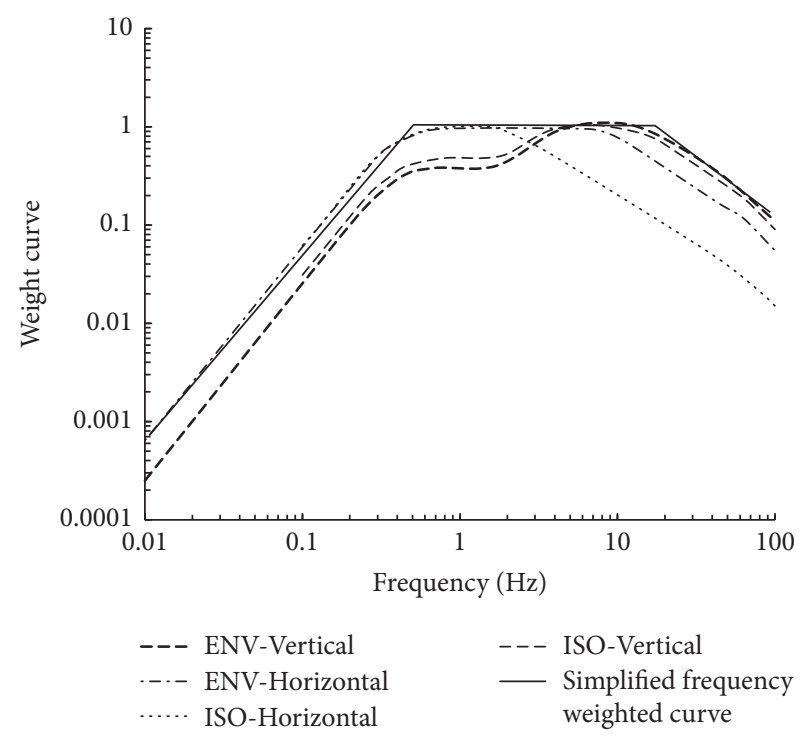

FIgURE 12: The simplified frequency-weighted curve.

A comparison of the results of these studies shows that although the results are in different forms, but the meaning of the expression is similar. In the lower frequency range (i.e., $<4 \mathrm{~Hz}$ ), the frequency-weighted value is small indicating that these vibration signals are small after weighting and they have little impact on the human body. In general, the biological effect of vibrations on the human body is mainly caused by the resonance with the human organs and the whole body whose natural frequency is larger than $4 \mathrm{~Hz}$. Thus, the human body is not sensitive to vibration lower than $4 \mathrm{~Hz}$.

For vibration signals with higher frequencies (i.e., 4 $80 \mathrm{~Hz}$ ), the weightages are higher. This is because, for this band, it has greater effect on the human body. Although the body is most sensitive to the vibration frequency within 4 $8 \mathrm{~Hz}$, the natural frequencies of many organs in the human body are in the higher frequency range. Hence, the vibration signals with higher frequencies can cause a variety of bad human subjective experiences. In addition, for the vibration generated by the open-air blasting, the energy of ground motion is mainly concentrated in the high frequency band (i.e., $4 \sim 80 \mathrm{~Hz}$ ), which is the main component of the blasting vibration energy [33].

For blasting vibrations greater than $80 \mathrm{~Hz}$, the human body is not very sensitive to these frequencies. This is because even before these vibrations are transmitted to the human body, most of them have already been absorbed by the clothes and shoes. The vibrations may not even reach the body skin. So, the human body may not feel the vibrations. Thus, the impact on the human body is small.

The frequency-weighted method as described above is suitable for vibration acceleration, but the calculation is complicated [7, 18, 22]. For the transient blasting vibration, the duration is very short. The frequency-weighted method can be simplified without any significant effect on the calculation results. Figure 12 shows the existing frequency weighting curve. It can be seen that, in the vertical direction, 
TABLE 4: The vibration energy weighting coefficient of each frequency band of human response.

\begin{tabular}{lccccc}
\hline Sequence number & 1 & 2 & 3 & 4 & 6 \\
\hline Frequency range $(\mathrm{Hz})$ & $<10$ & $10 \sim 20$ & $20 \sim 40$ & $40 \sim 80$ & $>80$ \\
Weighting coefficient $\eta_{E_{i}}$ & 1 & 0.93 & 0.49 & 0.25 & 0 \\
\hline
\end{tabular}

the weighting coefficients are the same. For the weighting coefficients in the horizontal direction greater than $3 \mathrm{~Hz}$, there are minor differences, but the variations are the same. Since the duration of the blasting vibration is short, more than $90 \%$ of the energy is concentrated in $10 \sim 80 \mathrm{~Hz}$. The envelope of frequency weighting curves can be used to linearize the frequency weighting curve, as shown in Figure 12 and Table 4. Using the simplified method, the effect on the calculated blasting vibration energy is very small, and the calculation process is greatly simplified. Further, the frequency weighting of the human body under the action of the blasting vibration can be unified with the blasting vibration response of the building.

Therefore, by considering different human body absorbing levels for different frequency components of the blasting vibration energy, the energy in each band is multiplied by the weighting coefficients of human vibration response, and the frequency-weighted absorbed blasting vibration energy in a human body can then be determined.

$$
E_{f}=\sum_{i=1}^{i=n} E_{f_{i}} \cdot \eta_{E_{i}},
$$

where $E_{f}$ is the frequency-weighted absorbed blasting vibration energy in a human body at different parts of the building, $E_{f_{i}}$ is the $i$ th band frequency-weighted response energy of the structure, and $\eta_{E_{i}}$ is the $i$ th band frequency component of the human vibration response-weighted coefficients.

The blasting seismic waves propagate forward in three directions (i.e., horizontal radial, horizontal tangential, and vertical). The traditional methods use physical parameters such as the vibration velocity and acceleration to evaluate the blasting vibration comfort. With these methods, only one vibration peak in each of the three directions can be considered. However, the blasting vibration comfort evaluation method developed in this study is based on the energy principle. The energy index is used as a scalar index, in which the vibration energies in the three directions are added together giving the total vibration effect, which is only an assumption. For the transient blasting vibration, the total vibration energy can be determined by adding the vibration energies from the three directions, as follows:

$$
E_{t}=E_{f x}+E_{f y}+E_{f z}
$$

where $E_{t}$ is total blasting vibration energy from all three directions absorbed by a human body in different parts of a building and $E_{f x}, E_{f y}$, and $E_{f z}$ are the respective human frequency-weighted blasting vibration energy from the horizontal radial, horizontal tangential, and vertical directions.

\section{Discussions}

For the traditional blasting vibration comfort indexes, such as the blasting vibration peak intensity and VDV, the disadvantages include little consideration of various factors, complex calculation procedure, lack of close combination of the blasting vibration characteristics, and the vibration characteristics of buildings and humans. Multistorey building has different sensitivity to energy components with different frequencies in the blasting seismic waves. There is amplification effect for selective frequencies. The traditional comfort indexes do not and cannot consider this characteristic of the building. Hence, the evaluation results by different indexes and criteria are large. In practice, the different blasting vibration comfort evaluation methods and standards may give different conclusions; some of results can be opposite to each other. Therefore, in this study, an ABVE index for comfort evaluation has been developed. Through analysis of a typical 4-storey brick-concrete building and human vibration characteristics, the elevation amplification effect on the ABVE index and the quantitative impact factors for different frequencies have been determined. Through correcting the ABVE evaluation index quantitatively, the total blasting vibration energy and its frequency components absorbed by a human body at different floors of the building can be accurately calculated. As the blasting vibration characteristics and vibration characteristics of buildings and humans have been combined, the ABVE evaluation index is objective in the evaluation of the blasting vibration comfort. In the analysis of the vibration characteristics of multistorey buildings, this study has analyzed a typical 4-storey brick-concrete building. In reality, due to the diversity of building types, the impact on the blasting vibration energy varies. Based on the research ideas in this work, future blasting vibration monitoring and theoretical research can be carried out so as to determine the factors that affect different types and heights of buildings by the blasting vibration energy. Then, the blasting vibration energy in different parts of buildings with different types and heights can be determined.

\section{Conclusions}

By monitoring numerical simulation and theoretical analysis of the blasting vibration, the response characteristics and the elevation amplification effect of different frequency components of the blasting vibration energy in blasting seismic waves have been investigated. The results show that blasting vibration energy is greater at higher floor. Based on the structural and seismic wave characteristics, the amplification degree has been determined. These characteristics should be taken into account in the evaluation of the blasting vibration comfort. Through monitoring the blasting vibration of a typical 4-storey building, the amplification coefficients for different floors have been determined. The response characteristics of the building to different energy components in the blasting seismic wave have been investigated. It has been found that there is extreme amplification of the energy component with frequency that is close to the natural frequency of the structure. On the other hand, the 
energy components with frequencies lower than the natural frequency essentially remain unchanged, and there is suppression for the energy components with higher frequencies. The weighting coefficients of response to different frequencies in the typical 4-storey building have been determined. The quantitative corrected coefficients have been determined for the absorbed blasting vibration energy and frequency components. Combining with the human vibration, a new body frequency-weighted simplified method has been developed. By summing up all the blasting vibration energies in all directions, the total blasting vibration energy absorbed by a human body at different floors has been determined. This index is more accurate in the quantitative evaluation of the blasting vibration comfort.

\section{Conflicts of Interest}

The authors declare that they have no conflicts of interest.

\section{Acknowledgments}

This work is supported by the National Natural Science Foundation of China (no. 51009104), the National Science and Technology Support Program of China (no. 2014BAB03B00), and Research Foundation for Young Teachers of Sichuan University (no. 2016SCU11039).

\section{References}

[1] Y. F. Yan, S. H. Chen, Q. H. Zhang, and W. L. Gao, "Research status and Prospect of comforbaleness of blasting seismic effect, in the eleventh session of the China Coal Society blasting academic conference papers set," China Coal Society blasting professional committee, pp. 15-20, 2010.

[2] Z.-G. Song, Y. Bai, and W.-L. Jin, "Vibration serviceability analysis of buildings near the area of blasting operation," Journal of Vibration and Shock, vol. 29, no. 9, pp. 129-133, 2010.

[3] Z. Y. Zhang, W. X. Zhang, and X. X. Wu, Modern hydraulic engineering blasting, China Water Power Press, Beijing, China, 2003.

[4] F. J. Lucca, "Tight construction blasting: ground vibration basics, monitoring, and prediction," 2003, https://assets.lawrenceks.org/assets/agendas/cc/2004/11-23-04/11-23-04H/blasting_ tight_construction_whitepaper.pdf.

[5] Q. Li, L. Qiao, G. Dasgupta, S. Ma, L. Wang, and J. Dong, "Blasting vibration safety criterion analysis with equivalent elastic boundary: based on accurate loading model," Shock and Vibration, vol. 2015, Article ID 604683, 10 pages, 2015.

[6] W. Zhen-Xiong, G. Wen-Bin, L. Ting, L. Jian-Qing, X. JingLin, and L. Xin, "Blasting vibration generated by breakingblasting large barriers with EBBLB," Shock and Vibration, vol. 2016, Article ID 7503872, 2016.

[7] Q. Yao, X. G. Yang, and H. T. Li, "Research, Prospect of the Assessment Methods of Comfort due to Blasting Vibration," Journal of Vibration and Shock, vol. 35, no. 22, pp. 152-160, 2016.

[8] J. Egan, J. Kermode, M. Skyrman, and L. L. Turner, "Ground vibration monitoring for construction blasting in urban areas, Final Report," Caltrans, p. 11, 2001.

[9] J. Loeb and D. D. Tannant, "Urban Construction Blasting in Canada-Complaints and Associated Municipal Bylaws," Civil Engineering and Architecture, vol. 2, p. 10, 2014.
[10] Standard, Australian, AS 2187.2: Explosives-Storage and Use, part 2, 2006.

[11] Standard, British, BS 7385-2: evaluation and measurement for vibration in building: part 2: guide to damage levels from ground borne vibration, 1993.

[12] A. K. Raina, A. Haldar, A. K. Chakraborty, P. B. Choudhury, M. Ramulu, and C. Bandyopadhyay, "Human response to blastinduced vibration and air-overpressure: an Indian scenario," Bulletin of Engineering Geology and the Environment, vol. 63, no. 3, pp. 209-214, 2004.

[13] B. Lusk, An analysis and policy implications of comfort levels of diverse constituents with reported units for blast vibrations and limits: closing the communication gap [Ph.D. thesis], University of Missouri-Rolla, Rolla, Mo, USA, 2006.

[14] A. J. Petro and D. A. Anderson, "Blast vibration problems: where do we go from here?" Journal of Mines, Metals and Fuels, vol. 34, no. 11, pp. 502-505, 1986.

[15] A. T. Spathis and A. Brodbeck, "Future directions in ground vibration and airblast control within australian regulatory context," in Proceedings of the Thirty-First Annual Conference on Explosives and Blasting Technique, pp. 263-275, International Society of Explosives Engineers, Cleveland, Ohio, USA, 2005.

[16] F. Chiapetta and A. Van Vreden, "Vibration/air blast controls, Damage criteria, record keeping and dealing with complaints," in Proceedings of the 9th Annual BME Conference on Explosives, Drilling and Blasting Technology, CSIR Conference Centre, Pretoria, South Africa, 2000.

[17] C. Kuzu and E. Guclu, "The problem of human response to blast induced vibrations in tunnel construction and mitigation of vibration effects using cautious blasting in half-face blasting rounds," Tunnelling and Underground Space Technology, vol. 24, no. 1, pp. 53-61, 2009.

[18] Q. Yao, X. Yang, and H. Li, "Comparative analysis on the comfort assessment methods and standards of blasting vibration," Journal of Vibroengineering, vol. 17, no. 2, pp. 1017-1036, 2015.

[19] DIN 4150-2, Structure Vibration-Human exposure to Vibration in Buildings, Deutsches Institut Fur Normung, 1999.

[20] ISO 2631, Mechanical vibration and shock-evaluation of human exposure to whole-body vibration. Part 1: general requirement, International Organization for Standardization, Geneva, 1997.

[21] ISO 2631, Mechanical vibration and shock-evaluation of human exposure to whole-body vibration. Part 2: Vibration in buildings $(1 \mathrm{~Hz}$ to $80 \mathrm{~Hz})$, International Organization for Standardization, Geneva, 2003.

[22] Q. Yao, X. Yang, and H. Li, "Residential comfort assessment due to blasting vibration," Journal of Vibroengineering, vol. 16, no. 2, pp. 674-684, 2014.

[23] Z. G. Song, A new annoyance-based vibration comfort design theory on engineering structures [Ph.D. thesis], Zhejiang University, Zhejiang, China, 2003.

[24] Technical Basis for Guidelines to Minimise Annoyance due to Blasting Overpressure and Ground Vibration, Australian and New Zealand Environment Council, Canberra, Australia, 1990.

[25] Z. Y. Zhang, N. H. Yang, and W. B. Lu, "Progress of Vibration Control Technology in China," Blasting, vol. 30, no. 2, pp. 25-32, 2013.

[26] L. Yu, "Safety influence of blasting vibration on multistory building," Journal of Railway Engineering Society, vol. 32, no. 3, pp. 86-89, 2015.

[27] D. D. Li and Z. D. Deng, "Evaluation of the effects of blasting vibration on humans in the rock excavation of CMICT dock," Engineering Blasting, vol. 12, no. 2, pp. 82-84, 2006. 
[28] Y. G. Wu, C. P. Wu, and Y. Xie, "Impact assessment of indoor living environment based on the harmful effect of blasting vibration," Nonferrous Metals (Mining Section, vol. 65, no. 4, pp. 67-70, 2013.

[29] S. Chen, Z. Zhang, and J. Wu, "Human comfort evaluation criteria for blast planning," Environmental Earth Sciences, vol. 74, no. 4, pp. 2919-2923, 2015.

[30] Y. Zhang and Y. Zhang, "Research on vibration velocity responses of surface building under the condition of blasting excavation in tunnel," Journal of Earthquake Engineering and Engineering Vibration, vol. 30, no. 6, pp. 112-119, 2010.

[31] Z. W. Wang, S. H. Dai, and H. Gao, "Dynamic response of the frame construction building to the open-pit blasting seismic waves," Journal of Safety and Environment, vol. 15, no. 3, pp. 111115, 2015.

[32] N. E. Wierschem, S. A. Hubbard, J. Luo et al., "Response attenuation in a large-scale structure subjected to blast excitation utilizing a system of essentially nonlinear vibration absorbers," Journal of Sound and Vibration, vol. 389, pp. 52-72, 2017.

[33] Y. Qiang, Y. Xingguo, and L. Hongtao, "A method for evaluating the comfort during blasting vibration based on energy absorbing principle," Journal of Vibration and Control, 2017.

[34] H. Li, W. Lu, D. Shu, X. Yang, and C. Yi, "Study of energy attenuation law of blast-induced seismic wave," Chinese Journal of Rock Mechanics and Engineering, vol. 29, supplement 1, pp. 3364-3369, 2010.

[35] P. K. Singh, P. M. Roy, and A. Sinha, "Standardization of Blast Vibration Damage Threshold for the Safety of Residential Structures in Mining Area in," 2006.

[36] R. M. Wheeler, "How millisecond delay periods may enhance or reduce blast vibration effects," Mining Engineering, vol. 40, no. 10, pp. 969-973, 1988.

[37] S. W. Hu and T. C. Miao, Structural vibration theory and its application, China Architecture Building Press, China, 2005.

[38] D. Vamvatsikos and M. Dolšek, "Equivalent constant rates for performance-based seismic assessment of ageing structures," Structural Safety, vol. 33, no. 1, pp. 8-18, 2011.

[39] "Blast vibration monitoring on anchored walls and within boreholes," International Journal of Rock Mechanics and Mining Sciences \& Geomechanics Abstracts, vol. 25, no. 1, p. A32, 1988.

[40] J. F. Wiss and R. A. Parmelee, "Human perception of transient vibrations, Journal of the Structural Division," ASCE, vol. 100, pp. 773-787, 1974.

[41] T. M. Murray, "Acceptability criteria for occupant induced floor vibrations," Sound and Vibration, vol. 13, no. 11, pp. 24-30, 1979.

[42] C. H. Dowding, "Construction Blasting," Construction Blasting, pp. 366-378, 2000.

[43] D. E. Siskind, M. S. Stagg, J. W. Kopp et al., Structure Response and Damage Produced by Ground Vibrations from Surface Blasting, Report of Investigations - United States, Bureau of Mines, Wash, USA, 1980.

[44] B. Ellingwood and A. Tallin, "Structural serviceability: Floor vibrations," Journal of Structural Engineering (United States), vol. 110, no. 2, pp. 401-418, 1984.

[45] EN. CEN, 12299: Railway ApplicationsRide Comfort for PassengersMeasurement and Evaluation, Railway Applications-Ride Comfort for Passengers-Measurement and Evaluation, 12299, 2009. 


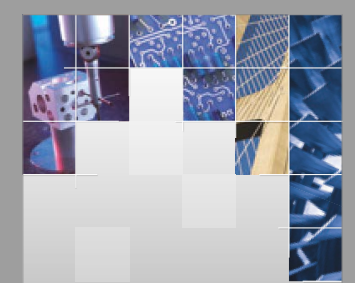

\section{Enfincering}
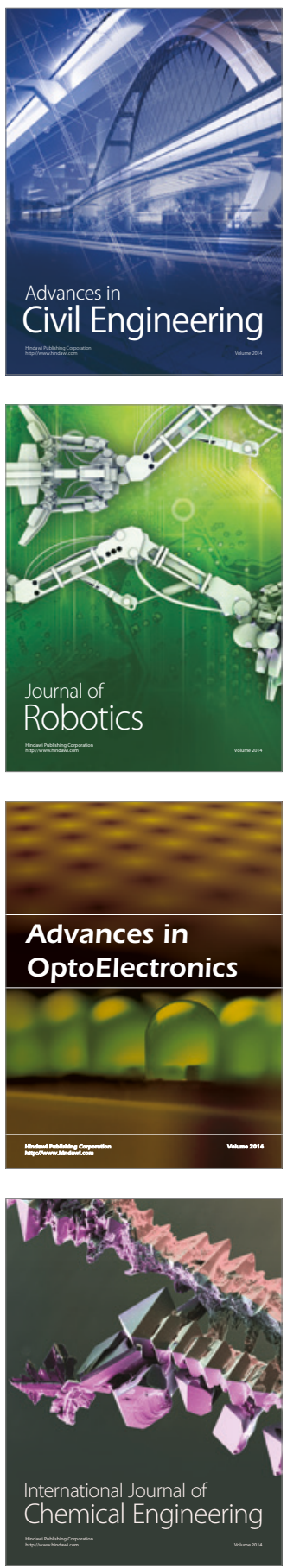

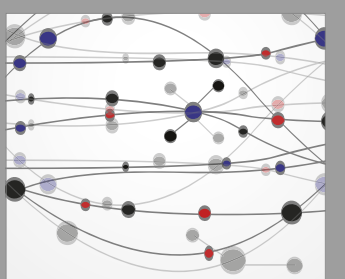

The Scientific World Journal

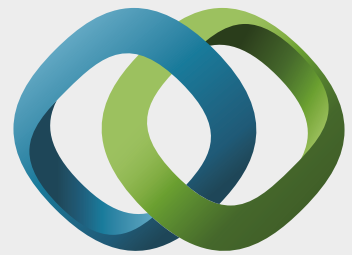

\section{Hindawi}

Submit your manuscripts at

https://www.hindawi.com
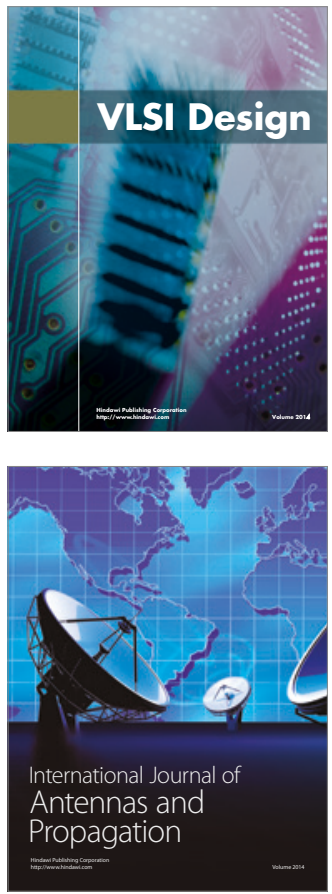

\section{Rotating}

Machinery
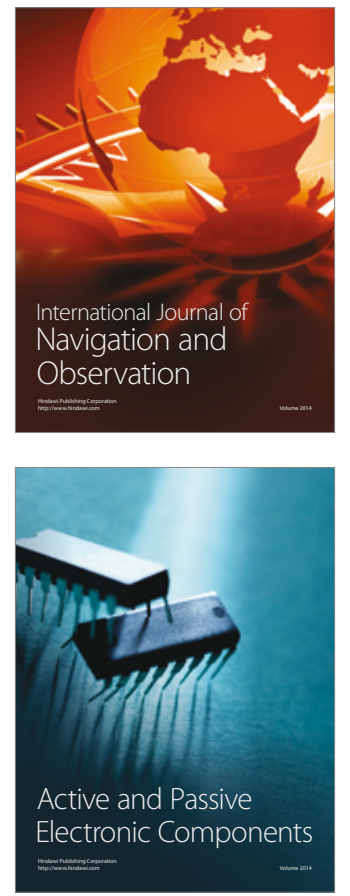
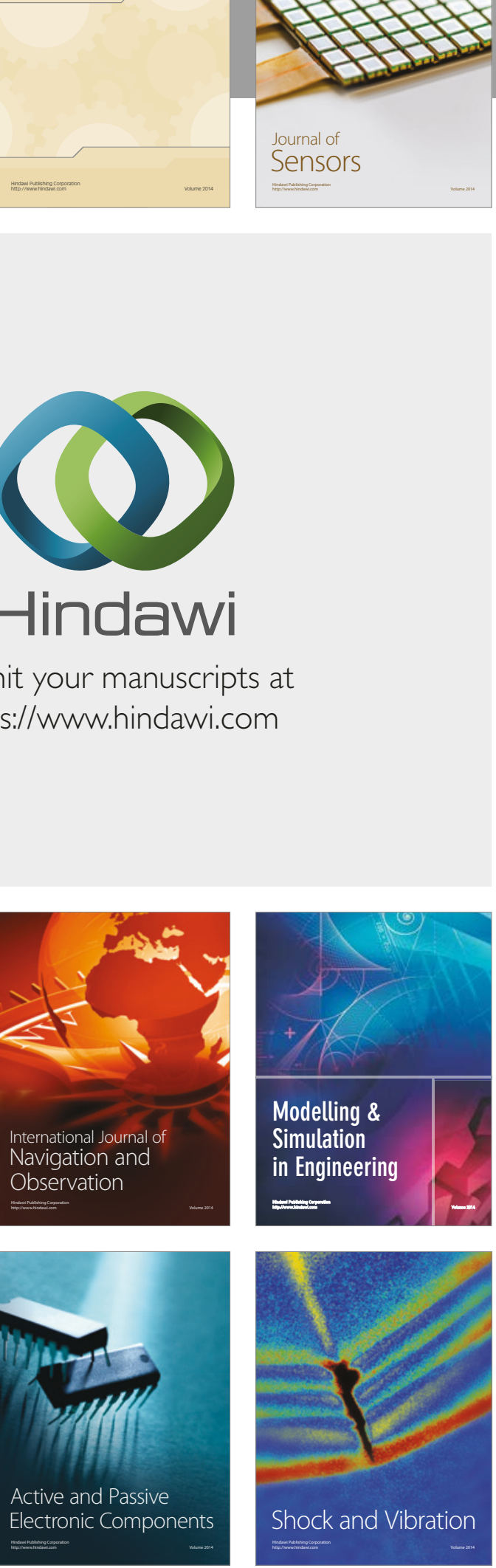
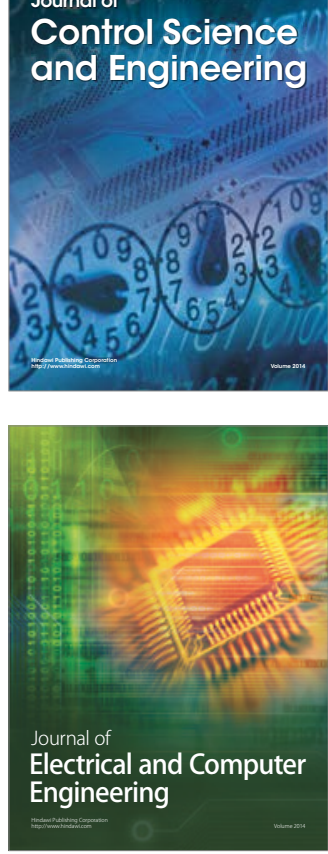

Distributed

Journal of

Control Science

and Engineering
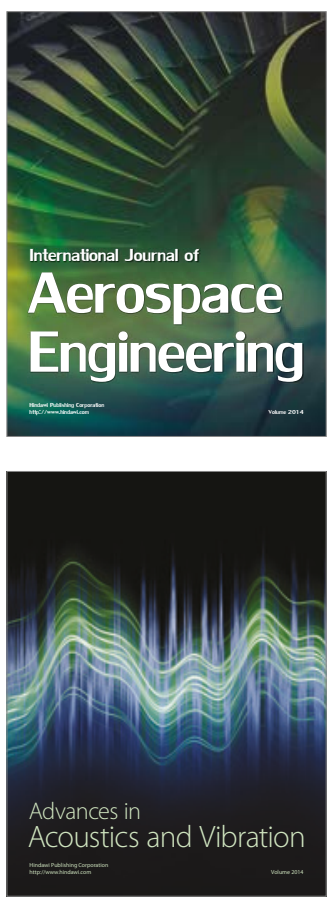

Sensor Networks 